\title{
SBFPO: o ambiente da discussão técnico-científica nacional do setor
}

\author{
CARLOS EDUARDO FERREIRA DE CASTRO(1), TAIS TOSTES GRAZIANO(2) \\ Q MARIA ESMERALDA PAYÃO SOARES DEMATTÊ(3)
}

Até o final da década de 70 , apesar de a pesquisa e o ensino em floricultura já estarem sendo praticados em várias instituições, como Instituto Agronômico, Biológico, de Economia Agrícola, universidades estaduais e federais, assim como em vários Jardins Botânicos, era desarticulada e, de certa forma, descompromissada com o setor produtivo; cada profissional atuava em sua instituição, de acordo com o possível, quer pela competência de seus pesquisadores e professores, pelos recursos disponíveis, ou pela estrutura física existente.

Em julho de 1979, pesquisadores da Universidade de Viçosa, articulados com outras instituições de pesquisa e ensino, buscando conhecer o trabalho dos demais pesquisadores e organizar melhor a pesquisa, realizaram o I Encontro de Pesquisadores em Floricultura e Plantas Ornamentais, em Viçosa, MG. O objetivo do encontro foi promover o congraçamento do disperso grupo de técnicos que, em tempo parcial ou integral, dedicava-se à pesquisa e ao ensino na área. Até então, a inexistência de uma associação técnico-científica atuante em todas as secções correlatas à floricultura, conduzia à pulverização de esforços convergentes às atividades do setor. Os técnicos se filiavam a sociedades afins, e os trabalhos científicos eram publicados em periódicos variados, sem continuidade, o que sobremaneira dificultava a sua plena divulgação, adoção e seu conhecimento.

Assim, durante esse Encontro, foi fundada a Sociedade Brasileira de Floricultura e Plantas Ornamentais (SBFPO), que passou a congregar profissionais e organizações interessados no desenvolvimento da floricultura brasileira, sob a concepção da abordagem holística. Além disso, trouxe apoio e estímulo ao trabalho técnico e científico no setor, divulgando os resultados obtidos em pesquisas, e cooperando com as pessoas físicas ou jurídicas na solução de problemas técnicos.

Participaram da criação da Sociedade Brasileira de Floricultura e Plantas Ornamentais, Luiz Carlos Lopes (MG), Maria Esmeralda S. P. Demattê (SP), Hildebrando Lopes dos Santos (MG), Heloisa Mattana Saturnino (MG), Luiz Gomes Correia (MG), Letícia Scardino Scott de Faria (MG), Izaura Telles de Menezes (SP), Maria Alice Bueno de Souza (SP), Manoel Vaz Costa (RS), René Luiz de Arruda (SP), Rita de Cássia Bezerra Guedes (CE), Rosa Maria G. Cardoso (SP), Taís Tostes Graziano (SP), Thomas Van Leeuven (SP), Ana da Glória C. Caiado (ES), Everardo Barbosa de Castro (RJ), Francisco Ullmann (MG), Francisco Ullmann Neto (MG), Airton Shiguekazu Arikita (SP), Antônio Perotti (PR), Arthur César Duarte (RJ), Carlos Frederico Gertum Pereira (RS), Célia Mendes Botelho (BA), César Roberto Lamonega (SP), Eliane Chatuni Mantovani (MG), Fernando Mendes Lamas (SP), Fernando Ribeiro Gomes (RJ), Guilherme Ceratti Ferreira (RS), Hildo Rafaeli (RS), José Carlos N. França (RJ), Mariza Côrtez Duarte (RJ), Maria Luiza Tucci (SP), Maria do Rosário de Lana Leite (MG), Marlene de Oliveira Sabini (MG), Marilda Mendes Pinto Petrechen (SP), Mário Arruda Mendes

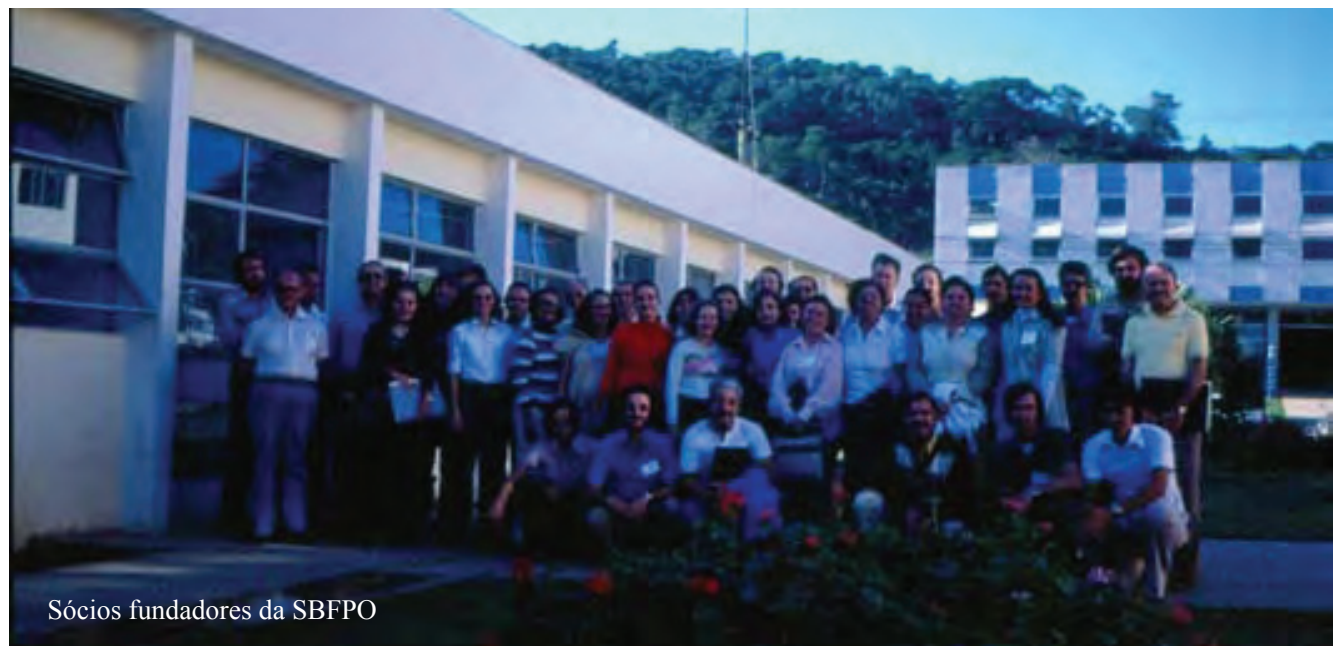

\footnotetext{
${ }^{(1)}$ Pesquisador Científico, Instituto Agronômico, Campinas (SP). Foi presidente da SBFPO, entre 1987 e 1991 . Também presidiu o $6^{\circ}$ e o $10^{\circ}$ CBFPO . ${ }^{(2)}$ Pesquisador Científico, Instituto Agronômico, Campinas (SP). Foi presidente da SBFPO, entre 1999 e 2005 . Também presidiu o $13^{\circ}$ CBFPO. ${ }^{(3)}$ Docente aposentada da UNESP - Jaboticabal (SP). Foi presidente da SBFPO, entre 1991 e 1995. Presidiu o I Simpósio Internacional sobre Palmeiras Ornamentais
} 
(MG), Nelson Pereira Leite (MG), Ney Pessanha Pacheco (RJ), Odorico Neves da Silva (MG), Olga Coelho Ullmann (MG), Palmira Regina Righetto Rolim (SP), Paulo Azevedo Berutti (MG), Paulo Roberto Nogueira Prata (MG), Raul Ubirajara Euclides (MG), Roberto da Silva Ramalho (MG) e Tiago Gomes Teixeira Neto (DF).Observado o seu raio de ação, a SBFPO promoveu até o presente, como atividades de grande expressão, 16 (dezesseis) Congressos Brasileiros, o I Encontro de Professores das Áreas de Floricultura, Plantas Ornamentais e Paisagismo das Faculdades de Agronomia do Estado de São Paulo, o I Encontro Nacional de Floricultura e Plantas Ornamentais, o I Simpósio Brasileiro de Floricultura e Plantas Ornamentais e co-promoveu o $1^{\circ}$ Simpósio Brasileiro sobre Recursos Genéticos de Plantas Hortícolas, o $1^{\circ}$ Simpósio Internacional sobre Palmeiras Ornamentais, o I International Symposium on New Floricultural Crops e a Jornada Nacional de Atualização Sobre o Cultivo do Antúrio. Além disso, co-patrocinou, até 1983, as reuniões bimensais do Grupo Paulista de Pesquisadores em Floricultura e Plantas Or- namentais, além de ter promovido inúmeras reuniões técnicas, palestras, fórum de debates e encontros de caráter regional em diversos estados do país.

A partir de 1995, a Sociedade passa a editar a Revista Brasileira de Horticultura Ornamental-RBHO -, periódico semestral, valioso na publicação de trabalhos de pesquisa e na divulgação de ciência e tecnologia direcionadas à Floricultura e ao paisagismo. Com tiragem de 1000 exemplares, foram publicados 11 volumes e 17 números na forma impressa, distribuídos gratuitamente a todos os seus sócios e a bibliotecas de escolas técnico-agrícolas, faculdades de Agronomia, Jardins Botânicos e instituições de pesquisa ligadas à agricultura, além de servir no intercâmbio com outras Sociedades Científicas, nacionais e internacionais. A partir de 2005, passou a ser editada na forma digital, já tendo mais sete números e um suplemento publicados. Hoje, a RBHO é também publicada em versão eletrônica, no endereço www.sbfpo.com.br/rbho.

Em seus 30 anos de existência, a SBFPO teve suas Diretorias assim constituídas:

\section{$1^{a}$ Diretoria (1979-1984)}

Presidente: Luiz Carlos Lopes, UFV, Viçosa (MG).

Vice-Presidente: Hildebrando Lopes dos Santos, EMATER (MG).

$1^{\circ}$ Tesoureiro: Luiz Gomes Correia, EMATER (MG).

$2^{\circ}$ Tesoureiro: Ana da Glória Costa Caiado, UFV, Viçosa (MG).

$1^{\circ}$ Secretário: Roberto da Silva Ramalho, Belo Horizonte (MG).

$2^{\circ}$ Secretário: Heloisa Mattana Saturnino, EMATER (MG).

\section{$2^{a}$ Diretoria:(1984-1987)}

Presidente: Hamilton Dias Bicalho, ESALQ/USP, Piracicaba (SP).

Vice-Presidente: Maria Alice de Lourdes Bueno de Souza, UNESP - Botucatu (SP).

$1^{\mathrm{o}}$ Tesoureiro: Rosiris Bergemann de Aguiar Silveira, IBT, São Paulo (SP).

$2^{\circ}$ Tesoureiro: Rosa Maria Gayoso Cardoso, IB, São Paulo (SP).

$1^{\circ}$ Secretário: Maria Luiza Tucci, CATI, Campinas (SP).

$2^{\circ}$ Secretário: Guanabara Paques Barros Pitta, IB, São Paulo (SP).

\section{$3^{\text {a }}$ Diretoria (1987-1991)}

Presidente: Carlos Eduardo Ferreira de Castro, IAC, Campinas (SP)..

Vice-Presidente: Maria Esmeralda S. Payão Demattê, UNESP - Jaboticabal (SP)..

$1^{\circ}$ Tesoureiro: Rosiris Bergemann de Aguiar Silveira, IBT, São Paulo (SP).

$2^{\circ}$ Tesoureiro: Guanabara Paques Barros Pitta, IB, São Paulo (SP).

$1^{\circ}$ Secretário: Taís Tostes Graziano, UNESP - Jaboticabal (SP).

$2^{\circ}$ Secretário: Atelene Normann Kämpf, UFRRS, Porto Alegre (SP).

Secretario Executivo: Antonio Fernando Caetano Tombolato, IAC, Campinas (SP).

\section{4ª Diretoria: (1991-1993)}

Presidente: Damares Beatriz de Suna Rodrigues, UFRPE, Recife (PE).

Vice-Presidente: Marcelo Ataíde da Silva, IPA, Recife (PE).

$1^{\circ}$ Tesoureiro: José Barbosa Cabral, IPA, Recife (PE).

$2^{\circ}$ Tesoureiro: Lectícia Scardino Schott Faria, UFBA, Salvador (BA).

$1^{\circ}$ Secretário: Rosa Lima Mariano, Recife (PE).

$2^{\circ}$ Secretário: Ana Guedes Goulart, Recife (PE).

\section{$5^{a}$ Diretoria (1993-1995)}

Face a dissolução da Diretoria anterior, a SBFPO foi dirigida, por dois anos, até realização de eleição, em 1995, por um Conselho constituído por Carlos Eduardo Ferreira de Castro, Luiz Antonio Ferraz Matthes e Yuri Tavares Rocha 


\section{$6^{a}$ Diretoria (1995 - 1999)}

Presidente: Maria Esmeralda Soares Payão Demattê, UNESP, Jaboticabal (SP).

Vice-presidente: Ana Maria Liner Pereira Lima, ESALQ/USP, Piracicaba (SP).

$1^{\circ}$ Secretário: Gláucia Moraes Dias Tagliacozzo, IAC, Campinas (SP).

$1^{\circ}$ Tesoureiro:. Rosiris Bergemann de Aguiar Silveira, IBT (SP).

$2^{\circ}$ Tesoureiro: .Kathia Fernandes Lopes Pivetta, UNESP, Jaboticabal (SP).

Secretária Executiva: Tais Tostes Graziano, IAC, Campinas (SP).

\section{$7^{a}$ Diretoria (1999- 2005)}

Presidente: Tais Tostes Graziano, IAC, Campinas, (SP).

Vice-presidente: Carlos Eduardo Ferreira de Castro, IAC, Campinas (SP).

$1^{\circ}$ Secretário: Roberval de Cassia Ribeiro, Esalq, Piracicaba (SP).

$2^{\circ}$ Secretário: Ana Maria Molini Costa, IAC, Campinas (SP).

$1^{\mathrm{o}}$ Tesoureiro: Rosiris Bergemann de Aguiar Silveira, IBT (SP).

$2^{\circ}$ Tesoureiro: Marcelo Chenoft, Holambra (SP).

Secretária Executiva: Ana Maria Molini Costa, IAC, Campinas (SP).

A 7 a Diretoria foi alterada em 2003, ficando assim constituída:

Presidente: Tais Tostes Graziano, IAC, Campinas (SP).

Vice-presidente: Carlos Eduardo Ferreira de Castro, IAC,Campinas (SP).

$1^{\circ}$ Secretário: Giulio Cesare Stancato, IAC, Campinas (SP).

$2^{\circ}$ Secretário: Luiz Antonio Ferraz Matthes, IAC (SP).

$1^{\circ}$ Tesoureiro: Rosiris Bergemann de Aguiar Silveira, IBT (SP).

$2^{\circ}$ Tesoureiro: Gláucia Moraes Dias Tagliacozzo, IAC, Campinas (SP).

Secretária Executiva: Charleston Gonçalves, UPD Ubatuba/APTA, Ubatuba (SP).

\section{Atual Diretoria, iniciada em 2005:}

Presidente: Antonio Fernando Caetano Tombolato, IAC, Campinas (SP).

Vice-presidente: Maria Esmeralda Soares Payão Demattê, UNESP, Jaboticabal (SP).

$1^{\circ}$ Secretário: José Marcos Leme, Doutorando FEAGRI/UNICAMP, Campinas (SP).

$2^{\circ}$ Secretário: José Luiz Mosca, CNPAT/EMBRAPA, Fortaleza (CE).

$1^{\mathrm{o}}$ Tesoureiro: Gláucia Moraes Dias Tagliacozzo, IAC, Campinas (SP).

$2^{\circ}$ Tesoureiro: Ana Maria Liner Pereira Lima, ESALQ/USP, Piracicaba (SP).

Secretária Executiva: Roberta Pierry Uzzo, IAC, Campinas (SP).

Os eventos patrocinados pela Sociedade Brasileira de Floricultura e Plantas Ornamentais, de âmbito nacional, despertaram grande interesse na comunidade científica e em profissionais que têm na floricultura o seu campo de atuação. Em ordem cronológica os principais eventos da SBFPO foram:

\section{Congresso da Sociedade Brasileira de Floricultura e Plantas Ornamentais}

O I Congresso foi realizado em julho de 1980, em Campinas (SP) e contou com a participação de 141 congressistas. Foram apresentados 31 trabalhos científicos, dos quais 11 foram publicados na íntegra, na forma de Anais.

\section{Congresso da Sociedade Brasileira de Floricultura e Plantas Ornamentais}

O II Congresso aconteceu também em Campinas (SP), em outubro de 1981, conjuntamente ao XXIX Congresso da American Society for Horticultural Science e ao XXI Congresso Brasileiro de Olericultura, tendo 426 inscritos. Foram apresentados 22 trabalhos na área de floricultura, 10 dos quais integralmente publicados nos Anais dos eventos.

III Congresso da Sociedade Brasileira de Floricultura e Plantas Ornamentais

O III Congresso foi sediado em Salvador (BA), em julho de 1982, e contou com 184 participantes. Foram apresentados 23 trabalhos, sendo 16 publicados na íntegra.

\section{$4^{0}$ Congresso Brasileiro de Floricultura e Plantas Or- namentais}

O $4^{\circ}$ Congresso, realizado em 1983, no Rio de Janeiro (RJ), contou com a participação de 217 congressistas. Foram apresentados 41 trabalhos técnico-científicos dos quais 22 foram publicados nos Anais do evento.

\section{Congresso Brasileiro de Floricultura e Plantas Or- namentais}

No transcorrer do V Congresso, conclave conjunto ao II Encontro Nacional de Orquidófilos e Orquidólogos, em Recife (PE), em março de 1985, os 123 participantes tiveram a oportunidade de assistir à apresentação de 16 trabalhos. 


\section{Encontro Nacional sobre Floricultura e Plantas Orna-} mentais

O Encontro Nacional foi realizado em outubro de 1986, em Porto Alegre (RS), e reuniu aproximadamente 400 participantes.

Objetivos: estimular a produção de plantas ornamentais como atividade agrícola alternativa para pequenos proprietários; incentivar floricultores já estabelecidos a partir da divulgação de novas técnicas de produção; levantar problemas e possíveis soluções referentes ao uso e manejo da paisagem, bem como assuntos relativos ao direito ambiental.

\section{$6^{\circ}$ Congresso Brasileiro de Floricultura e Plantas Ornamentais}

O $6^{\circ}$ Congresso foi realizado em setembro de 1987 , no Instituto Agronômico, em Campinas (SP), com a participação de 427 congressistas. Foram apresentados 65 trabalhos sendo 22 publicados na íntegra nos Anais do evento. Durante o evento, foi realizado também o $2^{\circ}$ Encontro Nacional de Colecionadores de Plantas Vivas. Foram também realizados os Cursos "Paisagismo" e "Arranjos Florais", além de cinco excursões técnicas pós-congresso. Além disso, em parceria com a Prefeitura Municipal de Campinas e associações de produtores, foi organizada a Primeira Parada das Flores.

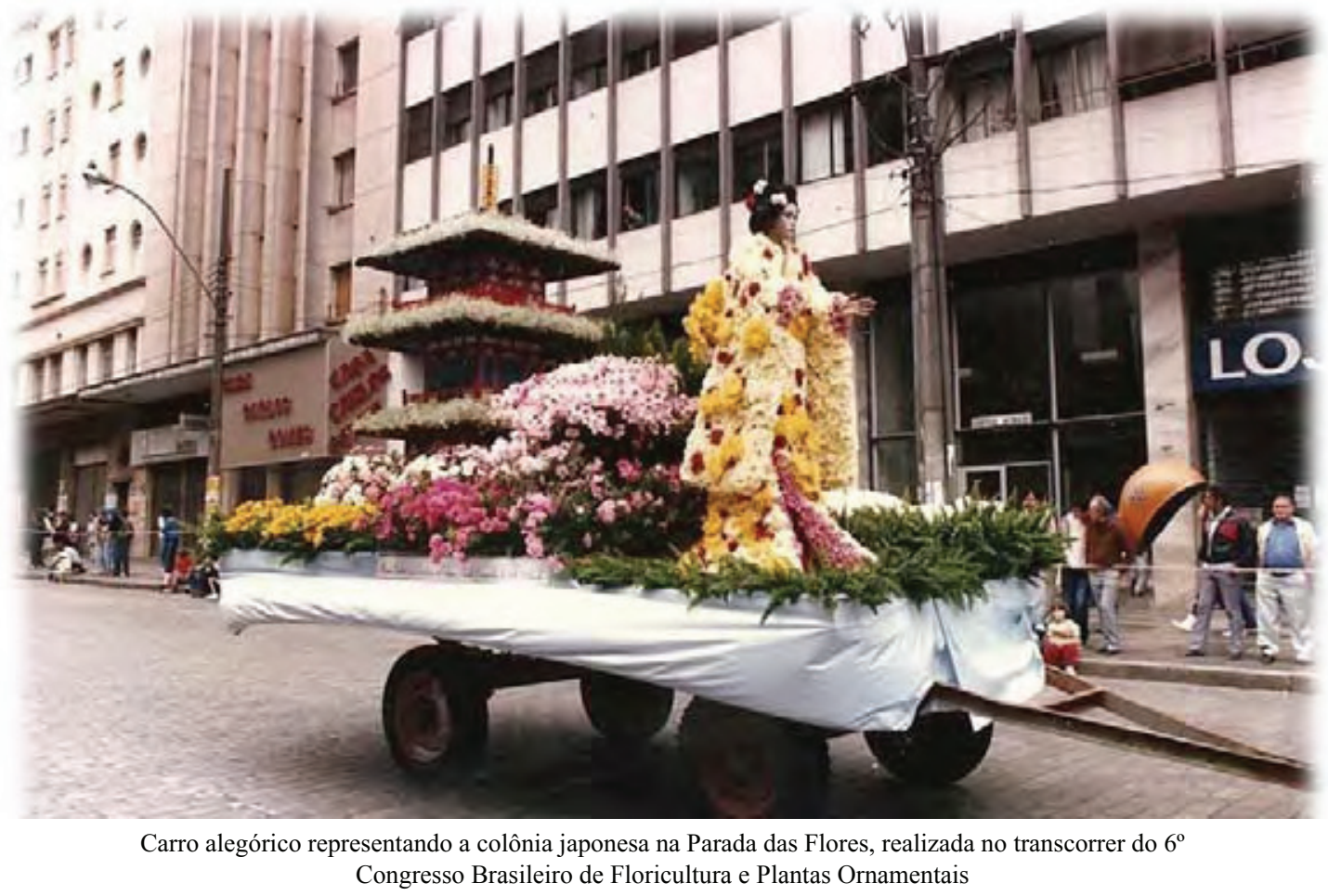

\section{Congresso Brasileiro de Floricultura e Plantas Or- namentais}

O VII Congresso, sediado em Viçosa (MG), aconteceu em setembro de 1989, com 220 inscritos e apresentação de 33 trabalhos. Nesse ano, foi decidido em Assembléia que a SBFPO deveria criar sua própria Revista TécnicoCientífica, como forma de publicar os trabalhos da área. Na ocasião, foi indicada a Pesquisadora Dra. Taís Tostes Graziano para dar início a esse projeto.

\section{$8^{\circ}$ Congresso Brasileiro de Floricultura e Plantas Or- namentais}

Realizado em Joinville (SC), em novembro de 1991, o $8^{\circ}$ Congresso reuniu 182 participantes, com a apresentação de 69 trabalhos.

\section{$1^{\circ}$ Simpósio Brasileiro de Floricultura e Plantas Or-}

\section{namentais}

O evento foi realizado em outubro de 1992 , na cidade de Maringá (PR), e reuniu 625 participantes. Foram apresentados 12 trabalhos técnico-científicos e, durante o evento, foi lançado o "Manual de Floricultura", com tiragem de 2.000 exemplares.

\section{$1^{\circ}$ Simpósio Internacional sobre Palmeiras Ornamentais}

Realizado em Jaboticabal (SP), em janeiro de 1993, o evento foi co-patrocinado pela International Society for Horticultural Science - ISHS. Dirigido a especialistas em palmeiras ornamentais, reuniu 98 participantes dos seguintes países: Brasil, Argentina, Portugal, Espanha, Costa Rica, Estados Unidos e Cuba. Foram apresentados 16 trabalhos técnico-científicos, todos publicados na íntegra na Acta Horticulturae - publicação internacional oficial da ISHS - volume 364, 1994. 


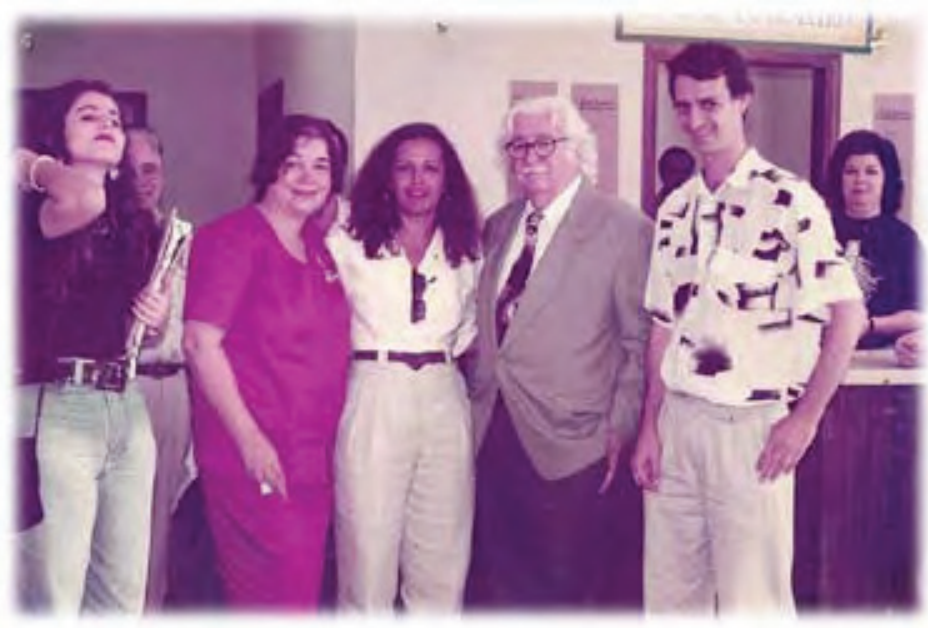

Comissão Organizadora do $1^{\circ}$ Simpósio Internacional sobre Palmeiras Ornamentais, com o ilustre palestrante Roberto Burle Marx

\section{$9^{\circ}$ Congresso Brasileiro de Floricultura e Plantas Or- namentais}

O $9^{\circ}$ Congresso, realizado em novembro de 1993 , em Recife (PE), teve 26 trabalhos técnico-científicos inscritos e contou com 72 participantes.

\section{I0 $^{\circ}$ Congresso da Sociedade Brasileira de Floricultura e Plantas Ornamentais}

O $10^{\circ}$ Congresso, que também sediou o I Simpósio Internacional de Zingiberales Ornamentais, foi realizado em setembro de 1995, em Campina (SP), e contou com a participação de 342 congressistas. Foram apresentados 81 trabalhos científicos, vários dos quais publicados na íntegra, na Revista Brasileira de Horticultura Ornamental. Assuntos como "A floricultura brasileira e seu planejamento estratégico", "Cenários da produção mundial de flores", "Ações do FRUPEX em floricultura", "Trade point e pers- pectivas de negócios", "Padronização de flores e plantas ornamentais", "Tecnologias avançadas em floricultura" e "Potencialidades de plantas bulbosas" foram abordados em palestras.

\section{$1^{\circ}$ Congresso da Sociedade Brasileira de Floricultura e Plantas Ornamentais e o Simpósio de Palmeiras}

$\mathrm{O} 11^{\circ}$ Congresso foi realizado de 11 a 16 de maio de 1997, em Belém (PA), e teve 84 participantes. Foram apresentados 41 trabalhos científicos, alguns dos quais publicados na íntegra, na Revista Brasileira de Horticultura Ornamental. Foram temas de palestras "O potencial da flora regional para utilização em paisagismo" e "Flores tropicais". Destacaram-se os debates sobre ensino e pesquisa em floricultura no Brasil e o Simpósio de Palmeiras, por ter reunido os grandes colecionadores e produtores de palmeiras de todo o Brasil.

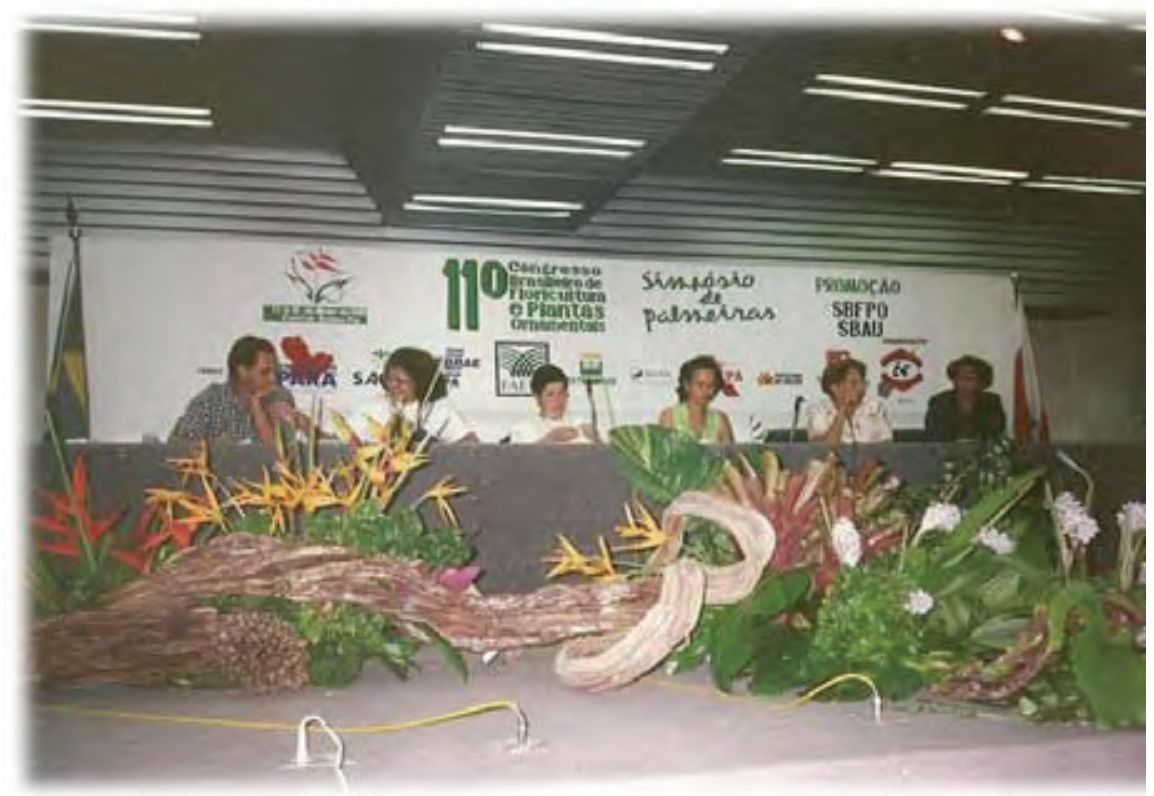

Sessão de abertura do $11^{\circ}$ Congresso Brasileiro de Floricultura e Plantas Ornamentais 
$12^{\circ}$ Congresso Brasileiro de Floricultura e Plantas Ornamentais

O $12^{\circ}$ Congresso foi realizado de 12 a 17 de setembro de 1999, em Jaboticabal (SP), e contou com a participação de 327 congressistas. Foram apresentados 125 trabalhos científicos, vários sendo integralmente publicados na Revista Brasileira de Horticultura Ornamental.

\section{$13^{\circ}$ Congresso Brasileiro de Floricultura e Plantas Or- namentais}

$\mathrm{O} 13^{\circ}$ Congresso foi realizado em São Paulo, $\mathrm{Ca}$ pital, de 17 a 19 de outubro, juntamente com o $4^{\circ}$ Fórum Brasileiro de Exportadores de Flores e Plantas Ornamentais, durante a FIAFLORA 2001, reunindo 200 participantes e apresentação de 145 trabalhos científicos, classificados por tema: 15 sobre Paisagismo, 4 em Aspectos Econômicos e Mercadológicos, 14 em Pós-Colheita, 9 em Botânica, 7 em Fisiologia, 31 em Propagação, 25 em Produção, 13 em Fitossanidade, 25 em Melhoramento e Biotecnologia e 2 em Outros, publicados no Livro de Resumos.

\section{International Symposium on New Floricultural Crops}

O Simpósio foi realizado em Foz de Iguaçu (PR), de 26 a 30 de agosto de 2003, com o co-patrocínio da International Society for Horticultural Science - ISHS, com apresentação de 95 trabalhos científicos. Além dos resumos publicados nos Anais, os trabalhos permitiram a edição da Acta Horticulturae 683.

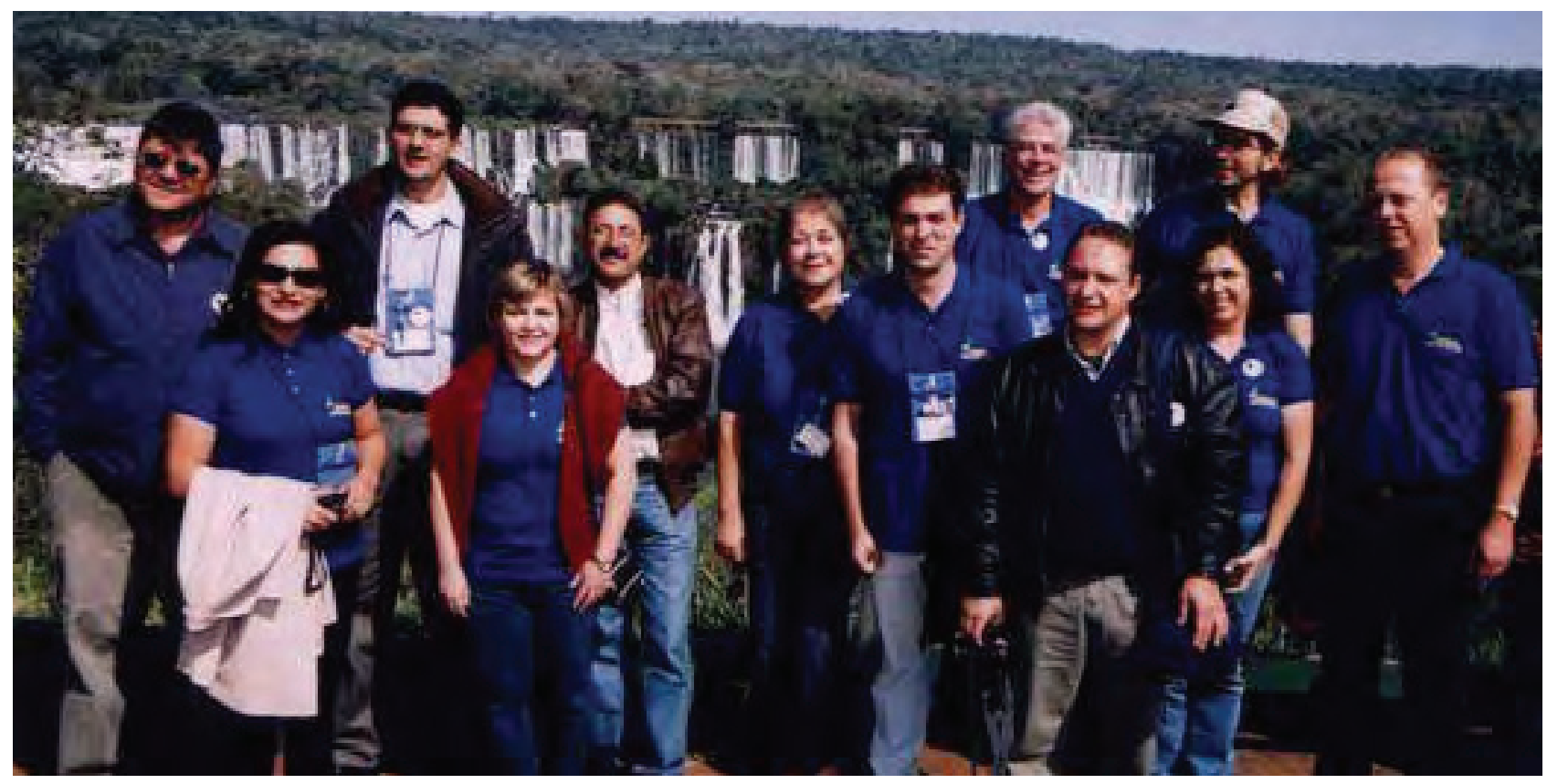

I International Symposium on New Floricultural Crops - Visita ao Parque Nacional de Foz do Iguaçu

\section{$14^{\circ}$ Congresso Brasileiro de Floricultura e Plantas Or- namentais}

O $14^{\circ}$ Congresso foi realizado de 5 a 8 de outubro de 2003, conjuntamente ao $1^{\circ}$ Congresso Brasileiro de Cultura de Tecidos de Plantas, em Lavras (MG), tendo 425 trabalhos científicos apresentados, vários sendo integralmente publicados na Revista Brasileira de Horticultura Ornamental.

\section{$15^{\circ}$ Congresso Brasileiro de Floricultura e Plantas Or- namentais}

O $15^{\circ}$ Congresso foi realizado de 7 a 12 de agosto de 2005 , conjuntamente ao $2^{\circ}$ Congresso Brasileiro de Cultura de Tecidos de Plantas e ao $45^{\circ}$ Congresso Brasileiro de Olericultura, em Fortaleza (CE) e contou com a participação de 1200 congressistas. Foram apresentados 1639 trabalhos científicos, 264 na área de Floricultura e Plantas Ornamentais, vários tendo sido integralmente publicados na Revista Brasileira de Horticultura Ornamental. O Congresso teve como tema central "Mercado de Qualidade". Cultivo orgânico, mercado de flores e hortaliças, paisagismo urbano e oportunidades de negócios internacionais estiveram entre os assuntos de destaque do evento.

Jornada Nacional de atualização sobre o cultivo do Antúrio

A Jornada foi realizada de 19 a 20 de outubro de 2005 , em Registro (SP), com a apresentação de 15 palestras específicas. Os textos das palestras proferidas no evento foram publicados na RBHO 10 (1/2).

\section{$16^{\circ}$ Congresso Brasileiro de Floricultura e Plantas Or- namentais}

O $16^{\circ}$ Congresso foi realizado de 10 a 15 de setembro de 2007, em Goiânia (GO), juntamente com o $3^{\circ}$ Congresso Brasileiro de Cultura de Tecidos de Plantas e $1^{\circ}$ Simpósio de Plantas Ornamentais Nativas ( $\left.1^{\circ} \mathrm{SPON}\right)$. Foram apresentados 356 trabalhos científicos, com vários integralmente publicados na Revista Brasileira de Horticultura Ornamental. O Congresso debateu assuntos como "O associativismo no agronegócio da floricultura no Brasil”, "A produção de flores tropicais como estratégia de competitividade no mercado mundial", "Certificação de plantas e flores, a transgenia 
em plantas ornamentais”, “A hibridação como estratégia de valor agregado ao produto" e "O paisagismo contemporâneo: conceitos e tendências".

\section{Jornada Nacional sobre o cultivo de Flores Tropicais}

A Jornada foi realizada de 7 a 8 de novembro de 2007, em Registro (SP), com a apresentação de 12 palestras específicas e a participação de 130 assistentes.

A classificação dos trabalhos apresentados nos eventos da SBFPO e daqueles publicados na RBHO possibilita, de modo indireto, estabelecer o perfil atual da pesquisa em floricultura no Brasil, centrada mais na biotecnologia, produção e pós-colheita.

Desde 1994, a SBFPO associou-se ao Instituto Brasileiro de Floricultura (IBRAFLOR), participando ativamente nas discussões e decisões dessa entidade, que hoje representa o setor em nível nacional. Também tem representação nas Câmaras Setoriais Estaduais e Nacional de Flores e Plantas Ornamentais. Conjuntamente à $\mathrm{ABH}$ - Associação Brasileira de Horticultura - e à SBF - Sociedade Brasileira de Fruticultura -, representa o país, na ISHS - International Society for Horticultural Science.

Fortalecidos pela representatividade ora exercida, os pesquisadores e professores têm trabalhado no sentido de or- ganizar melhor a pesquisa e o ensino, discutindo seu papel no desenvolvimento do setor, tanto no âmbito regional como nacional, e as estratégias a serem adotadas na busca de fontes de financiamento que garantam o desenvolvimento de seus projetos e a melhoria das condições físicas de pesquisa.

Nesse sentido, nos últimos anos, têm-se buscado em vários setores e programas, como $\mathrm{CNPq}$, Ministério da Agricultura, Pecuária e Abastecimento (MAPA), FAPESP, APEX, Sebrae, a formulação de políticas de desenvolvimento para o setor, uma vez que a carência de tecnologias modernas, geradas ou adaptadas para a horticultura ornamental, tem sido um obstáculo ao incremento do agronegócio. Ainda hoje, parte dos empresários envolvidos na produção desenvolve processo de tentativas, o que acarreta alguns prejuízos e retrocessos.

Indubitavelmente, os maiores e melhores fóruns de discussão dos assuntos correlatos à Ciência, Tecnologia e Inovação da floricultura brasileira, bem como o local de congraçamento de pesquisadores, professores, extensionistas, produtores rurais e interessados que atuam no setor, são os eventos técnico-científicos promovidos pela Sociedade Brasileira de Floricultura e Plantas Ornamentais. Durante seus 30 anos de existência, a SBFPO vem atuando como indiscutível farol do desenvolvimento tecnológico no País. 